\title{
Appraisal of Beneficiaries' Perspective on Opportunities and Barriers of NCD Clinics in a Coastal District of Kerala
}

\author{
Aranya GN ${ }^{1}$, Athirarani $\mathrm{MR}^{2}$, Sujitha Elavally ${ }^{3}$, Sairu Philip ${ }^{4}$ \\ ${ }^{1}$ Lecturer, Govt. School of Nursing, Govt. Medical College, Kozhikode. Kerala, ${ }^{2}$ Associate Professor ( CAP) \\ Govt. College of Nursing, Govt. Medical College, Thiruvananthapuram. Kerala, ${ }^{3}$ Assistant Professor, Govt. \\ College of Nursing, Govt. Medical College, Thiruvananthapuram. Kerala, ${ }^{4}$ Vice Principal, Professor and Head of \\ Department, Dept. of Community Medicine, Govt. TD Medical College, Alappuzha, Kerala
}

\begin{abstract}
Background: Non-Communicable diseases (NCDs) have become the main causes of morbidity and mortality in many developing countries. In India, NCD Clinics are set up by the guidelines of National Programme for Control of Diabetes, Hypertension, Cardiovascular Disease and Stroke (NPCDCS) for the control, prevention and treatment of NCDs. Govt of Kerala introduced the NCD clinics to compact the disease burden of the state in 2010 through the National Health Mission.
\end{abstract}

Objective: To appraise the beneficiaries' perspective on opportunities and barriers of NCD Clinics in Alappuzha district.

Methods: It was a qualitative study conducted over a period of 6 weeks among the people in the age group of 30 years and above residing in Ambalappuzha taluk. 28 in-depth interviews and 18 focus group discussions were conducted and the reviews of records in the primary health centres using a questionnaire were done. Thematic analysis of observations and percentage estimation of service indicators were done.

Result: The study revealed a cluster of four themes such as awareness about the services, availability, accessibility, acceptability of services and Satisfaction about the services. Although there is receptiveness to the services, barriers to mainstreaming also exist which persuade them not to utilise these services. In all PHCs the indicators for screening for NCDs are less than $80 \%$. Screening services should be strengthened more. So, the need to revamp the structure and systems to enhance the utilisation of the services of NCD Clinics is highlighted.

Keywords: NCD Clinics, Opportunities, Barriers, Kerala

\section{Introduction}

Non-Communicable Diseases (NCDs) are an increasing threat to public health posing heavy economic burden for health systems ${ }^{1,2}$. Currently, NCDs account for almost two-thirds of deaths globally and it is $61 \%$ of all deaths in India . ${ }^{3,4}$ WHO initiated many innovative and action-oriented responses and Government of Indiaintroduced a national program for controlling Non-communicable diseases called National Program for Prevention and Control of Cancer, Diabetes, Cardiovascular Diseases and Stroke (NPCDCS) in the second half of 2010. As per the programme, NCD clinics are conducted regularly in all PHCs in Kerala, the success of any programme depends on the acceptability and satisfaction of the beneficiaries ${ }^{6}$. The present study intends to appraise the beneficiaries' perspectives on opportunities and barriers of NCD clinics.

\section{Materials and Methods}

The study was conducted in Alappuzha district of Kerala using a qualitative research design. The population consisted of adults in the age group of $\geq 30$ years residing in the study area. They were grouped into four categories such as Utilisers of NCD clinics with NCD, Utilisers of NCD clinics without NCD, Non-utilisers of NCD 
clinics with NCD, Non-utilisers of NCD Clinics without NCD. Persons without NCD were also included as they are eligible for screening in the NCD clinics as per the NPCDCS guidelines. Among the six taluks of Alappuzha district, Ambalapuzha was selected randomly, out of the 16 Community Health Centres of Amabalapuzha taluk two CHCs were selected one each from the urban and rural area. The participants were chosen from all the ten PHCs coming under both CHCs. The utilisers of NCD clinics were approached either during their visit to the NCD clinics or tracked from the community with the help of NCD registers. The non-utiliser was selected from the field area through home visits. The Frontline health workers, ASHAs and JPHNs were utilised for the identification of non-utilisers from the field. The topic guides for Focus Group discussion (FGD) indepth interviews (IDI) were validated by experts and the participants were purposively chosen. The selection at this phase was purposive and the data were collected through FGD and IDI. The guides of FGD and IDI were validated by the subject experts before the administration in the sample. Before data collection, the gatekeepers were informed about the conduct of the study. A total of 28 IDIs and 18 FGDs were conducted. The venue for the conduct of FGD and IDI were selected as per the preference of the participants. There was representation from males and females from urban and rural areas. The number of members in a group ranged from 6 to 12 . The homogeneity of the participants in all FGDs was ensured for conducive group dynamics during the discussions. Probing and prompting questions, counter questioning, repetition, and summing up were used in the interviews to ensure that the information obtained was credible. A neutral attitude was maintained by the interviewer throughout the interview. Nonverbal observations during and immediately after the interviews were recorded as field notes. The researcher maintained a reflective diary throughout the study to note personal reflections, biases, and assumptions. The Analysis was done by Colaizzi 7 step data analysis method, which involves acquiring a sense of each transcript by reading and re-reading, extracting significant statements, formulating meaning from the statement, creating themes from the formulated meaning, defining and describing the phenomenon under study, identifying the fundamental structure and validating the data with suitable stakeholders. ${ }^{7}$ Semiquantitative analysis was done for the interpretation of the viewpoints of participants (Table1).

\section{Results}

The findings from FGDs and IDIs and were categorized as Opportunities and Barriers of NCD Clinics under the themes such as awareness about the service, availability and accessibility of services, Acceptability of services and Satisfaction about the services.

\section{Awareness about the services of NCD clinics}

\section{Ia. Opportunities}

A majority of utilizers (5+) and Non-Utilizers (4+) were aware of the services of NCD Clinics. They were informed about the clinics from health care professionals and community leaders. Some described primarily interpersonal information sources available to them including knowledge acquired through experience and from family, friends and colleagues.

"Once I had a bad headache and I fell and somebody took me to the hospital. My BP was high and after getting treatment from there, they informed me about the NCD Clinics and now I am a regular user of this clinic" Utiliser of NCD Clinics (FGD1)

\section{I b. Barriers}

During the interviews with participants, a few participants $(2+)$ from Non-utiliser category were found unaware about the services of NCD Clinics. Some (2+) of the non-utilisers reported needs for strategies like availing the new technologies such as social media for identifying the beneficiaries and reminding them about next check-ups.

"No health visitor came to my home. Nobody informed me about the NCD Clinics" - Non-Utiliser of NCD Clinics ( IDI 10 ). "I had heard about the clinics but I was unaware that it provides screening services to all above 30 years. I thought it is only for those who have the disease" -Non-utiliser of NCD Clinics $\left(F G D_{1}\right)$

\section{Availability and Accessibility of services}

Availability and Accessibility of services is the major element of the utilisation of services. The utilisation of the services would be better if services and facilities are easily available to the beneficiaries 


\section{II a. Opportunities}

A majority of utilisers (4+) and some of the nonutilisers $(2+)$ reported that the screening activities and registration are done in the subcentres. Almost all $(5+)$ utilisers and non-utilisers (5+) had an understanding about the importance of screening all the people at the age of 30 and above for Non-communicable diseases, to detect it and to start treatment as early as possible.

"Screening for Non-communicable diseases is essential. This helps to identify whether we have any disease or not and helps to change our dietary pattern" -Utiliser of NCD Clinics (IDI_).

\section{II b. Barriers}

A few participants across the utiliser $(2+)$ and nonuser $(2+)$ category expressed their displeasure, because of how the NCD Clinics are operated. They felt there was long waiting in the outpatient department and the subcentres did not open sometimes.

"The sub-centres will not be opened when we visit there on the same day which is being fixed by the health care people. It is one of the major faults from the side of the health care personnel" -Utiliser of NCD Clinics $\left(F G D_{1}\right)$

\section{Acceptability}

The acceptability of services is another reason for utilising the services of NCD clinics. People's preferences for utilising or not utilising the services were obtained to know about the opportunities and barriers.

\section{III a. Opportunities}

Almost all (5+) utilisers perceived the existing services as acceptable and they are ready to continue the services. Some opined that it is better to use government facilities than private. Some of the non-utilisers $(3+)$ say that as it is free of cost and is nearby so it is better to use the services than any other facilities.

"Most of the people coming here are poor and aged. In my opinion, it is better for all to utilise the services as it is the responsibility of the Government to take care of the health of the people so we get good care from there" -Utiliser of NCD Clinics with NCDs (IDI). "We have a very good health centre nearby then why should we go to any other place. We get all the things free of cost. My family will come here only"-Non-Utiliser of NCD Clinics without NCDs (IDI14)

\section{III b. Barriers}

The preference of a particular doctor is an important aspect. Some of the non-utilisers $(2+)$ opined that they prefer the same doctor to consult all the time they went to the health centre, which may not be possible in the NCD Clinics. Some had a preference to other systems of medicine. Some $(2+)$ from the non-utiliser category are afraid about allergies to the Allopathic medicines and some think that they get other diseases by taking the medications. Some participants $(2+)$ says that the investigations were done in government institutions sometimes shows false result so they are reluctant to utilise NCD Clinics.

"It is a difficult thing that we cannot see the same doctor when we come for next time so we have to explain all the things again. We cannot explain all the things to a new and unfamiliar doctor" -Utiliser of NCD Clinics with NCDs (IDI2)

\section{Satisfaction about the services.}

Satisfaction about the services available is one of the major factors which prompt the people to utilise or not to utilise it. It emphasizes patients' expectations of care and perceived quality of care. Different categories of people opined differently in the satisfaction component. These viewpoints lead to quantification the opportunities and barriers as given below.

\section{IV a. Opportunities}

Most of the utilisers (5+) express their satisfaction with the services of NCD clinics as it is easily available, accessible, and affordable to them. Most of the NonUtilisers (4+) expressed that they will utilise the services of NCD Clinics if they came across with any of the NCDs in future. Some suggest that they will be more satisfied if the old people get nutrition supplements through subcentres. It is observed that most of the beneficiaries were ready to pass information to the community if they or their family members start experiencing the benefits of NCD Clinics. 
"It's a good service which is affordable to us and we get it nearby. I am satisfied with the service. That's why I come again and again"-Utiliser of NCD Clinics $\left(I D I_{1}\right)$

\section{IV b. Barriers}

There are few $(2+)$ participants across the Nonutilisers' category, who expressed dissatisfaction regarding the services in NCD Clinics. They felt that medicines are not available, there is a long waiting period in the outpatients' department and the surroundings of clinics are not cleaned.

"We will get medicines but the most important medications will not be there, so we have to go outside for that. It will be costly too" -Non-Utiliser of NCD Clinics with NCDs $\left(I D I_{18}\right)$

Table 1: Qualifiers used for Semi quantitative Expression of Observations

\begin{tabular}{|l|l|l|}
\hline Adjectives used & Proportion of respondents & Qualifier used \\
\hline Very few & $<10 \%$ & $<1+$ \\
\hline Some & $10-24 \%$ & $1+$ \\
\hline Approximately half & $25-49 \%$ & $2+$ \\
\hline Majority or over half & $50-74 \%$ & $3+$ \\
\hline Most & $75-89 \%$ & $4+$ \\
\hline Almost all & $>90 \%$ & $5+$ \\
\hline
\end{tabular}

\section{Discussion}

Even though the people are aware of NCD clinics, they are not taking initiative to visit the clinics until the symptoms arise. There is need for additional efforts to improve the reach of services especially the screening services to the unreached. These findings are supported by another study which shows a significant association between health workers' visit with the utilization of the program. If initiations are taken for scaling up IEC activities, it will improve the utilization. There is only a small proportion percentage of people who are not aware of the services of NCD clinics. These findings differ from the finding of a similar study in Surender Nagar district Gujrat which reveals that the programme is new and hence awareness about this programme per se was low. Hence it would be worthwhile to conduct regular sensitization activities for the public so that they come back for follow up and utilize the services adequately [8]. The findings of the study have a lot of implications in the field of community health, research and administration. When the opportunities and barriers of NCD clinics are identified, necessary steps can be taken to combat the barriers through better planning of educational programmes and other interventions.

\section{Conclusion}

The study was intended to appraise the beneficiaries' perspective on opportunities and barriers of NCD clinics in Alappuzha district. The results of the study show that the NCD clinics in Sub centre, PHCs and CHCS help to deal with the prevailing NCD burden of the state more effectively. There is awareness about the services of NCD Clinics and the services are well perceived by them. Although there is receptiveness to the services, barriers to mainstreaming also remain which persuade them not to utilise these services. There is need for individual level of awareness regarding the screening and treatment services available which can be regularly given through community level volunteers and frontline health workers. Regular supply of medicines, maintaining standard of 
care, prompt and quality services, counselling regarding lifestyles and fear of adverse reactions of long-term medication can further improve the acceptability and satisfaction of services.

Ethical Considerations: The permission for the conduct of the study was obtained from the Institutional Ethics Committee and written informed consent were obtained from the participants.

\section{Financial support and sponsorship: NIL}

Conflicts of Interest: There are no conflicts of interest.

\section{References}

1. World Health Organization, Global status report on Non-Communicable Diseases 2010, A. Alwan, Editor. Geneva; 2010. [cited 2018 march.23] Available from http://apps.who.int/iris.

2. World Health Organization, Global status report on non-communicable diseases 2014, S.Mendis, Editor.Geneva; 2014. [cited 2018 march.23] Available from http://apps.who.int/iris

3. World Health Organization, Global status report on non communicable diseases 2017. [cited 2018 march.23] Available from: http://www.who.org/

4. Thankappan KR, Shah B, Mathur P, Sarma PS, Srinivas G, Mini GK, et al. Risk factor profile for chronic non-communicable diseases: results of a community-based study in Kerala, India. Indian J Med Res. 2010 Jan;131:53-63. [cited 2018 july 3] Available from https://www.ncbi.nlm.nih.gov/ pubmed/20167974

5. Mohan V, Sandeep S, Deepa R, Shah B, Varghese C. Epidemiology of type 2 diabetes: Indian scenario. Indian J Med Res. 2007 Mar;125(3):217-30 [cited 2019 Jun 15]. Available from: https://www.ncbi. nlm.nih.gov/pubmed/17496352

6. Jose R, Pisharady R, Benny PV , Zinia TN , Rema SD , Varghese S ,Sathyadas P I . Evaluation of non communicable disease control pilot programme of National Rural Health Mission in Thiruvananthapuram district.2013.[cited2018 march19]:Available at: https://www.researchgate. net/profile/Regi_Jose/publication /259173263

7. Morrow, R., Rodriguez, A. and King, N. (2015). Colaizzi's descriptive phenomenological method. The Psychologist, 28(8), 643-644.

8. Jasani P NimavatJ,Joshi J, Jadeja Y, Kartha G,A study on evaluation of Non-Communicable Disease Control Programme in Surendranagar District. 2012International Journal of Science and Research ISSN (Online): 2319-7064, 4, 2015 March [cited 2018 march.23] Available from: https://www.ijsr. net/archive/ v4i3/SUB152043.pdf 